\title{
Relation between coronary risk and coronary mortality in women of the Renfrew and Paisley survey: comparison with men
}

\author{
Christopher G. IsLes DAVID J. Hole Victor M. HAWTHORNE \\ ANTHONY F. LEVER
}

Most epidemiological and intervention studies in patients with coronary artery disease have focused on men, the assumption being that such data can be extrapolated to women. However, there is little evidence to support this belief.

We have completed a fifteen-year follow-up of 15399 adults, including 8262 women, who lived in Renfrew and Paisley and were aged $45-64$ years when screened between 1972 and 1976. We identified 490 deaths from coronary heart disease (CHD) in women and 878 in men. Women were more likely to have high cholesterol, to be obese, and to come from lower social classes than men, but they smoked less and had similar blood pressures. The relative risk-top to bottom quintile $(95 \% \mathrm{Cl})$ - of cholesterol for coronary death after adjustment for all other risk markers was slightly greater in women $(1.77[1.45,2 \cdot 16])$ than in men $(1.56[1.32,1.85])$, but absolute and attributable risk were lower. Thus, women in the top quintile for cholesterol had lower coronary mortality $(6 \cdot 1$ deaths per thousand patient years) than men in the bottom quintile ( 6.8 deaths per thousand patient years). Moreover, it was estimated that there would have been only 103 (21\%) fewer CHD deaths in women, yet 211 (24\%) fewer in men, if mortality had been the same for women and men in the lowest quintiles of cholesterol. Trends showing similar relative risks in these women, but lower absolute and attributable risks than in men, were present for smoking, diastolic blood pressure, and social class. There was no relation between obesity and coronary death after adjustment for other risks.

Our results suggest that some other factors protect women against CHD. The potential for women to reduce their risk of $\mathrm{CHD}$ by changes in lifestyle may be less than for men.

Lancet 1992; 339: 702-06.

\section{Introduction}

Rates of coronary heart disease (CHD) increase with age in both sexes but are higher in men than in women. ${ }^{1}$ Most population studies and intervention trials have focused on the relation between coronary risk and coronary disease, together with the effects of reducing cholesterol, in men. However, recommendations for prevention of coronary disease do not distinguish between men and women ${ }^{2}$ on the grounds that what is good for men is likely to benefit women. This approach could only be justified if the absolute and attributable risks of $\mathrm{CHD}$ were similar, and if preventive measures were effective in both sexes. To examine risk further, we have analysed the relation of coronary heart disease with plasma cholesterol, cigarette smoking, diastolic blood pressure, body mass index, and social class in a general population of 15399 middle-aged adults, including 8262 women, who were screened in Renfrew and Paisley between 1972 and 1976 and then followed up until the end of 1989.

\section{Methods}

The Renfrew and Paisley survey is a longitudinal health study of 15399 subjects, including 8262 women, who were aged 45 to 64 years when first examined between 1972 and 1976. The subjects were taken as representative of an urban population in the west of Scotland. The survey was preceded by a census and each man and woman between the ages of 45 and 64 years was visited and given an invitation to attend; $79 \%$ of eligible subjects in Renfrew and $78 \%$ of those in Paisley did so. During the first two years of follow-up, those not attending had higher mortality than those who did attend. Thereafter, mortality rates were similar in attenders and nonattenders.
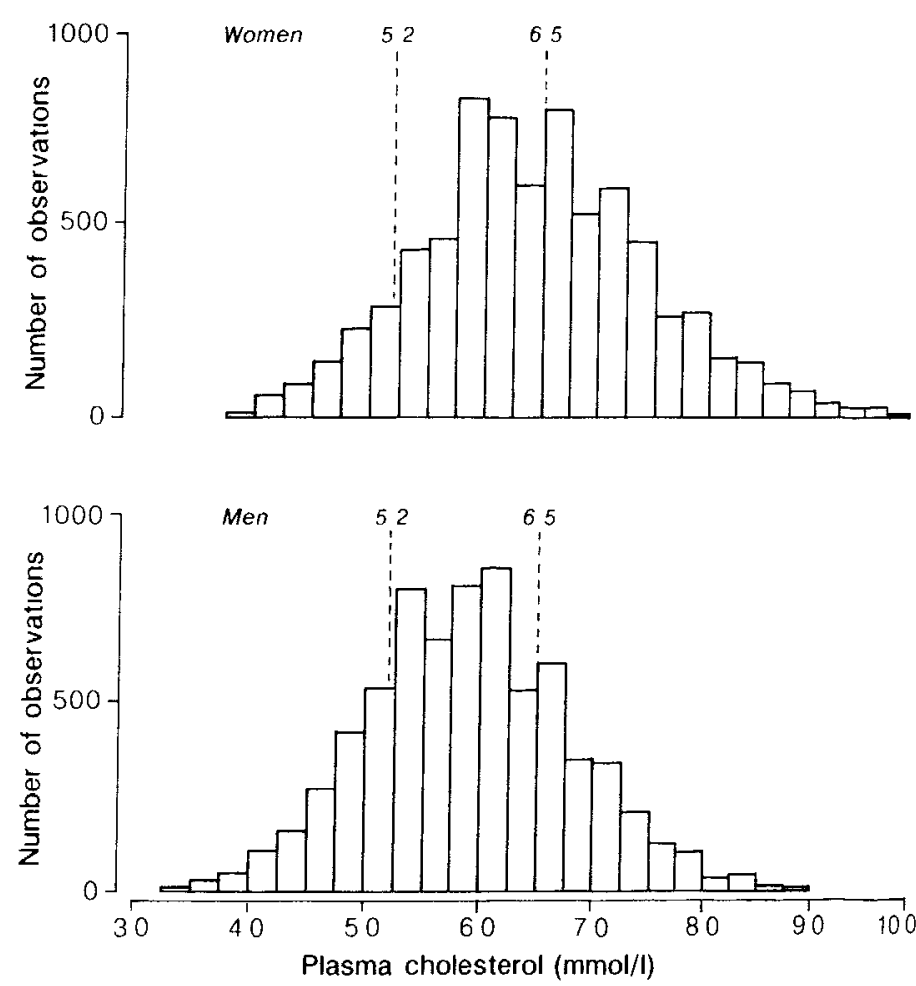

Fig 1-Distribution of plasma cholesterol among 8262 women and 7137 men aged 45-64 years.

Smoking habits were recorded by a standard questionnaire and measurements were made of height and weight (to give body mass index in $\mathrm{kg} / \mathrm{m}^{2}$ ), blood pressure (London School of Hygiene sphygmomanometer, diastolic phase $\mathrm{V}$ ), and non-fasting plasma cholesterol. Social class was determined by occupation, except for housewives and retired women whose husbands' or fathers' occupations were used instead in classification.

ADDRESSES: Dumfries and Galloway Royal Infirmary, Dumfries, UK (C. G Isles, FRCP); Cancer Surveillance Unit, Ruchill Hospital, Glasgow, UK (D. J. Hole, MSc); Department of Epidemiology, University of Michigan, Michigan, USA (Prof V.M. Hawthorne, $M D)$ : and MRC Blood Pressure Unit, Western Infirmary, Glasgow. UK (Prof A. F. Lever, FRCP) Correspondence to Dr C. G. Isles, Dumfries and Galloway Royal Infirmary, Dumfries DG1 4AP, UK. 


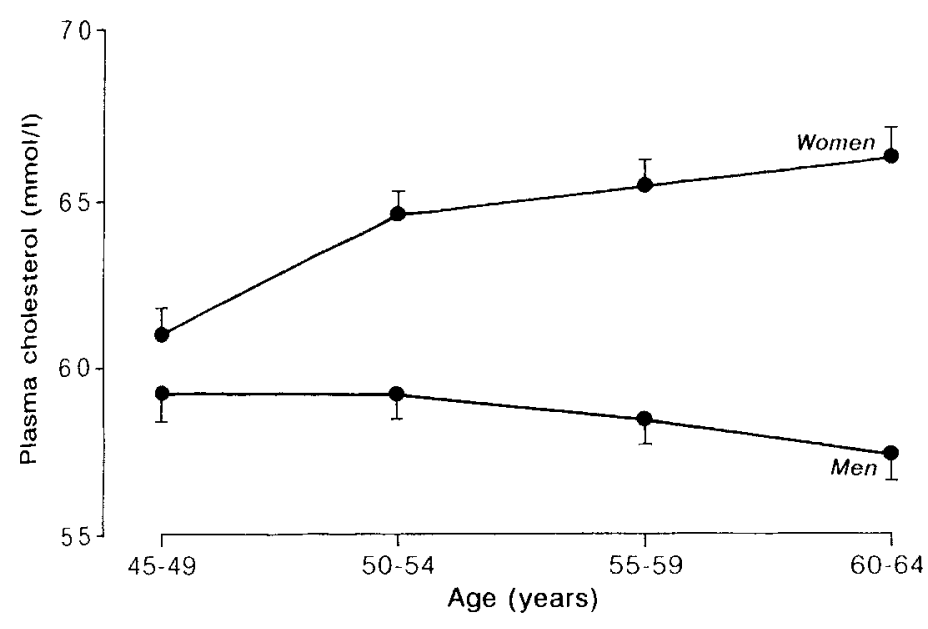

Fig 2-Mean $(99 \% \mathrm{Cl}$ ) plasma cholesterol in women and men.

Records kept with the Registrar General in Scotland ensured notification of a subject's death, provided it took place in the UK, together with the cause of death according to the 9th revision of the International Classification of Diseases (ICD) codes. $^{3}$ Although uncertainties about cause of death taken from the death certificate have been noted, ${ }^{4}$ we had previously assessed the methods of the Registrar General in a study of hypertensive patients. ${ }^{5}$ Notification from the Registrar General was virtually complete and coding comparisons of causes of death by the Registrar and by independent physicians yielded no important discrepancies. Full details of our methods have been published elsewhere. ${ }^{6}$

Our analysis concerns the relation between markers of coronary risk and coronary disease in women, and a comparison with better-known findings in men. For this study, we have taken 15-year mortality data based on $490 \mathrm{CHD}$ deaths in women and 878 CHD deaths in men (ICD codes 410-414). CHD mortality rates were calculated as deaths per 1000 patient years of follow-up, and then adjusted for all variables (age, smoking, cholesterol, diastolic blood pressure, body mass index, and social class), except for the variable of interest, before the data were arranged in quintiles. The quintile points for cholesterol were $5 \cdot 5,6 \cdot 1,6 \cdot 6$, and $7 \cdot 2 \mathrm{mmol} / \mathrm{l}$ in women, and $5 \cdot 0,5 \cdot 6,6 \cdot 0$, and $6.6 \mathrm{mmol} / \mathrm{l}$ in men. Corresponding values for diastolic blood pressure were $74,80,87$, and $95 \mathrm{~mm} \mathrm{Hg}$ in women and $74,81,88$, and $96 \mathrm{~mm} \mathrm{Hg}$ in men. Quintile points for body mass index were $22 \cdot 2,24 \cdot 2,26 \cdot 2$, and $28.9 \mathrm{~kg} / \mathrm{m}^{2}$ in women, and $23 \cdot 0,24 \cdot 9,26 \cdot 6$, and $28 \cdot 5 \mathrm{~kg} / \mathrm{m}^{2}$ in men. CHD mortality was also assessed by smoking category (zero, $1-14, \geqslant 15$ cigarettes per day, ex-smoker) and by social class ( 1 and 2, 3 non-manual, 3 manual, and 4 and 5). We applied a proportional hazards model to evaluate trends in mortality across each risk distribution after adjustment for other risk markers.

\section{Results}

\section{Prevalence of risk markers in women}

Fig 1 shows the distribution of plasma cholesterol in women and men. Mean (SD) values were higher in women $(6.43[1.09] \mathrm{mmol} / \mathrm{l})$ than in men $(5.87[0.96] \mathrm{mmol} / \mathrm{l})$. The proportion of women with cholesterol greater than $5 \cdot 2,6.5$, and $7.8 \mathrm{mmol} / 1$ was $89.0 \%, 47.8 \%$, and $11.2 \%$, respectively; corresponding values for men were $77.6 \%$, $26.3 \%$, and $3.3 \%$, respectively. The difference between the sexes was a result of higher cholesterol concentrations in older women than in older men (fig 2).

Women were less likely than men to smoke or to be heavy smokers (table I). Both average diastolic blood pressure and the proportion of subjects with a diastolic pressure greater than $90 \mathrm{~mm} \mathrm{Hg}$ were similar in men and women. More men than women were overweight (body mass index 25-29 $\mathrm{kg} / \mathrm{m}^{2}$ ) but a higher proportion of women were obese (body mass index $\left.>29 \mathrm{~kg} / \mathrm{m}^{2}\right) .{ }^{7}$ Although husbands and wives shared social class, among those who were unmarried a higher proportion of women belonged to social classes 4 and 5 (table I).
TABLE I-DISTRIBUTION OF RISK MARKERS AMONG WOMEN AND MEN

\begin{tabular}{|c|c|c|}
\hline - & $\begin{array}{c}\text { Women } \\
(n=8262)\end{array}$ & $\begin{array}{c}\text { Men } \\
(n=7137)\end{array}$ \\
\hline \multicolumn{3}{|l|}{ No (\%) subjects of smoking habit. } \\
\hline Non-smoker & $3824(45 \cdot 8)$ & $1189(16 \cdot 8)$ \\
\hline $1-14 /$ day & $1572(18 \cdot 8)$ & $981(13 \cdot 9)$ \\
\hline$\geqslant 15 /$ day & $2334(28 \cdot 0)$ & $3152(44 \cdot 7)$ \\
\hline Ex-smoker & $623(7.5)$ & $1736(24 \cdot 6)$ \\
\hline Mean $(S D) D B P(\mathrm{~mm} \mathrm{Hg})$ & $85(14)$ & $86(13)$ \\
\hline \multicolumn{3}{|l|}{ No (\%) subjects with $D B P$ : } \\
\hline$<90 \mathrm{~mm} \mathrm{Hg}$ & $5537(66 \cdot 3)$ & $4533(64 \cdot 2)$ \\
\hline $90-99 \mathrm{~mm} \mathrm{Hg}$ & $1631(19 \cdot 5)$ & $1460(20 \cdot 7)$ \\
\hline $100-109 \mathrm{~mm} \mathrm{Hg}$ & $784(9 \cdot 4)$ & $711(50 \cdot 1)$ \\
\hline$\geqslant 110 \mathrm{~mm} \mathrm{Hg}$ & $397(4 \cdot 8)$ & $350(5.0)$ \\
\hline $\operatorname{Mean}(S D) B M I\left(\mathrm{~kg} / \mathrm{m}^{2}\right)$ & $25 \cdot 8(4 \cdot 5)$ & $25.9(3.4)$ \\
\hline \multicolumn{3}{|l|}{ No (\%) subjects with $B M / \star$ : } \\
\hline$<18.5 \mathrm{~kg} / \mathrm{m}^{2}$ & $190(2 \cdot 3)$ & $53(0 \cdot 8)$ \\
\hline $18 \cdot 5-25 \cdot 0 \mathrm{~kg} / \mathrm{m}^{2}$ & $3830(45.9)$ & $2813(39.9)$ \\
\hline $25 \cdot 0-29 \cdot 0 \mathrm{~kg} / \mathrm{m}^{2}$ & $2697(32 \cdot 3)$ & $2995(42 \cdot 5)$ \\
\hline$\geqslant 29 \cdot 0 \mathrm{~kg} / \mathrm{m}^{2}$ & $1662(19.5)$ & $1194(16-9)$ \\
\hline \multicolumn{3}{|l|}{ No (\%) subjects of socia/ c/ass } \\
\hline $1+2$ & $1455(17-4)$ & $1333(18 \cdot 9)$ \\
\hline 3 non-manual & $1977(23 \cdot 7)$ & $834(11 \cdot 8)$ \\
\hline 3 manual & $1490(17.8)$ & $2816(39.9)$ \\
\hline $4+5$ & $3431(41 \cdot 1)$ & $2075(29 \cdot 4)$ \\
\hline
\end{tabular}

$\mathrm{DBP}=$ diastolıc blood pressure, $\mathrm{BMI}=$ body mass index.

$\star<185$ is underweight, 18 5-250 0 ideal; $25.0-29.0$ overweight $_{r} \geqslant 29.0$ obese $^{\text {? }}$

\section{Coronary risk and mortality}

There were $490 \mathrm{CHD}$ deaths in women and $878 \mathrm{CHD}$ deaths in men. Although menopausal status was not known for individual patients, only one female coronary death occurred before age 52 (the average age of menopause in the UK). Thus, most mortalities among women in our study were postmenopausal.

15-year CHD mortality by baseline plasma cholesterol and other coronary risk markers is shown in figs 3 and 4 . Plasma cholesterol, cigarette smoking, diastolic blood pressure, and low social class were positively and independently associated with CHD mortality in both sexes, whereas there was no relation between body mass index and CHD after adjustment for other risk markers.

The relative risk of coronary death (top to bottom quintile) was similar in both sexes (table II). In women, the absolute risk was less in that, for a given risk factor, women with high individual risks generally had a lower coronary mortality than men with low risks. Fig 3 shows that women with cholesterol concentrations above $7.2 \mathrm{mmol} / 1$ had a

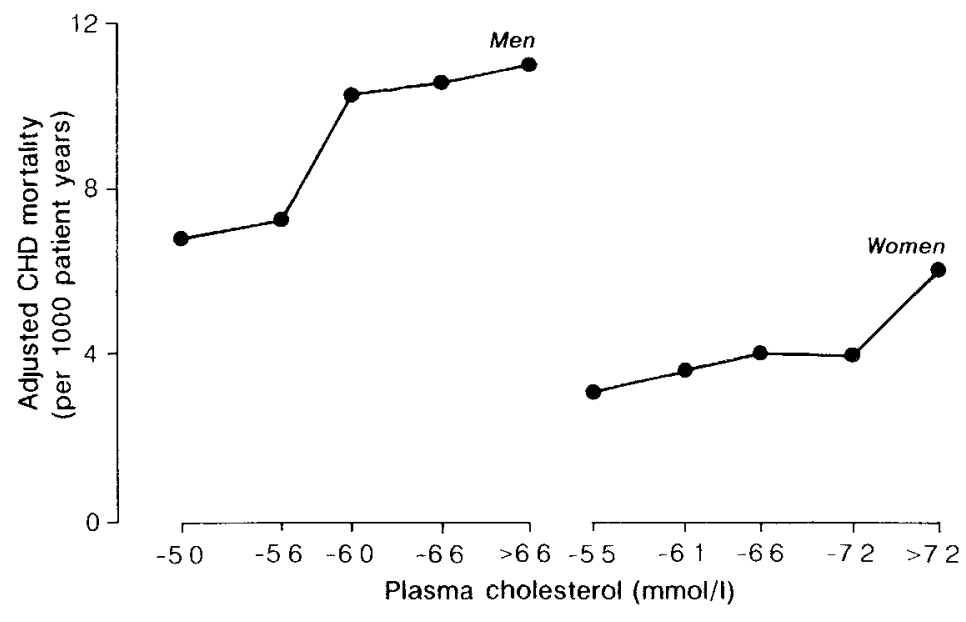

Fig 3-Adjusted CHD mortality in deaths per 1000 patient years for men and women by quintile of plasma cholesterol.

There were $490 \mathrm{CHD}$ deaths in women with a relative risk of 1.77 $(p<0.001)$. Corresponding figures for men were $878 \mathrm{CHD}$ deaths, relative risk $1.56(p<0.001)$. 


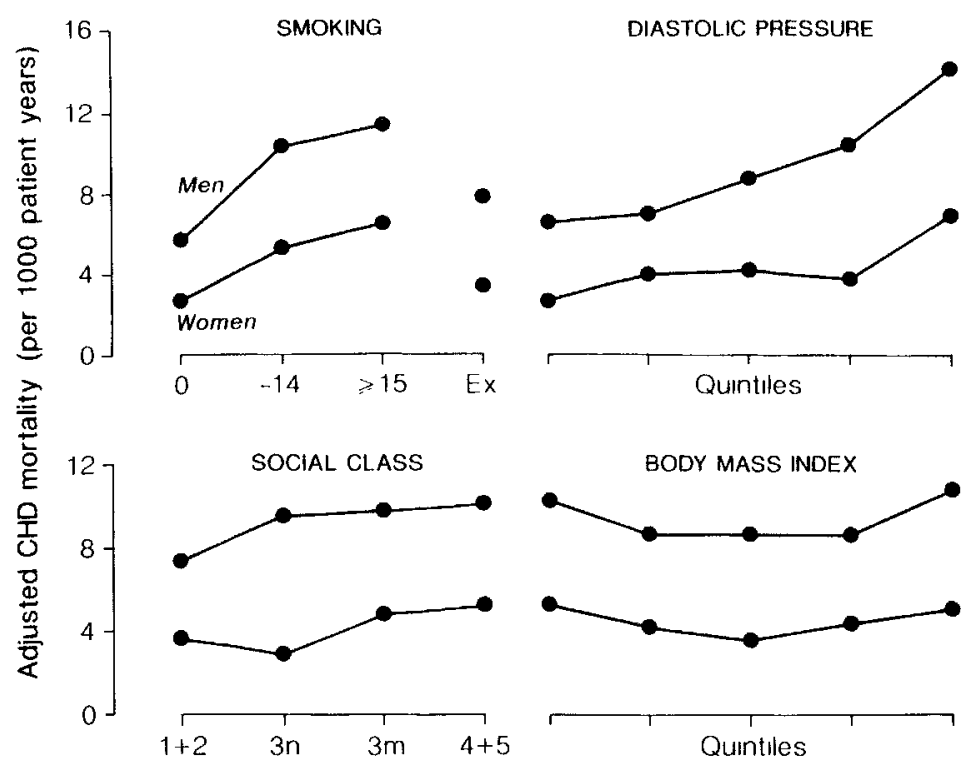

Fig 4 -Adjusted CHD mortality in deaths per thousand patient years for both sexes by cigarette smoking, diastolic pressure, social class, and body mass index.

$p<0.001$ for smoking, diastolic pressure, and social class No significant influence on CHD mortality was found for body mass index. For each of the four analyses risks were greater in men

lower risk of $\mathrm{CHD}$ than men with cholesterol values below $5.0 \mathrm{mmol} / 1$. Similar trends were present for blood pressure, smoking, and social class (fig 4).

The best estimate of the number of CHD deaths attributable to any given risk marker is known as attributable risk-ie, the number of $\mathrm{CHD}$ deaths that would not have taken place if the levels of that risk marker had been in the lowest category of risk. All attributable risks in our population were less in women than in men (table II). More lives could have been saved if the whole population had not smoked than by any other single intervention, assuming that these other measures would be completely effective in reversing risk (table II). Calculation of attributable risk for cholesterol indicated that there would have been $103(21 \%)$ fewer CHD deaths in women and $211(24 \%)$ fewer $\mathrm{CHD}$ deaths in men if the mortality of the whole group had been the same as that among women and men whose cholesterol concentrations were in the lowest quintile. Attributable risks for diastolic blood pressure and low social class are also shown in table II.

TABLE $\|$-RELATIVE AND ATTRIBUTABLE RISK OF CORONARY DEATH IN MEN AND WOMEN

\begin{tabular}{|c|c|c|c|c|}
\hline - & $\begin{array}{l}\text { Relative risk } \\
(95 \% \mathrm{Cl})\end{array}$ & $p$ & $\begin{array}{l}\text { Attribu } \\
\text { (death }\end{array}$ & $\begin{array}{l}\text { able risk } \\
\text { saved) }\end{array}$ \\
\hline \multicolumn{5}{|l|}{ Men } \\
\hline Cholesterol & $1.56(1.32,1.85)$ & $<0.001$ & $24 \%$ & $(211)$ \\
\hline Smoking & $2.03(1.64,2.52)$ & $<0.001$ & $40 \%$ & (351) \\
\hline $\begin{array}{l}\text { Diastolic blood } \\
\text { pressure }\end{array}$ & $2 \cdot 19(1 \cdot 74,2 \cdot 75)$ & $<0.001$ & $31 \%$ & \\
\hline Body mass index & $1.07(0.87,1.32)$ & NS & & \\
\hline Social class & $1.45(1 \cdot 17,1.80)$ & $<0.001$ & $25 \%$ & $(220)$ \\
\hline \multicolumn{5}{|l|}{ Women } \\
\hline Cholesterol & $1 \cdot 77(1 \cdot 45,2 \cdot 16)$ & $<0.001$ & $21 \%$ & (103) \\
\hline Smoking & $2.38(1.91,2.96)$ & $<0.001$ & $37 \%$ & (181) \\
\hline $\begin{array}{l}\text { Diastolic blood } \\
\text { pressure }\end{array}$ & $2.62(1.92,3.58)$ & $<0.001$ & $39 \%$ & (191) \\
\hline Body mass index & $0.95(0.72,1.26)$ & NS & & $\cdots$ \\
\hline Social class & $1.51(1 \cdot 14,1.99)$ & $<0.01$ & $32 \%$ & $(157)$ \\
\hline
\end{tabular}

NS, not-significant.

Relative risk for cholesterol, diastolic pressure, and body mass index is the ratio of the top to bottom quintile for each risk marker, for smokers it is the ratio of the rate for current smokers who smoke 15 or more cigarettes per day to the rate of lifelong non-smokers, for social class it is the rate for classes 4 and 5 combined to classes 1 and 2 combined

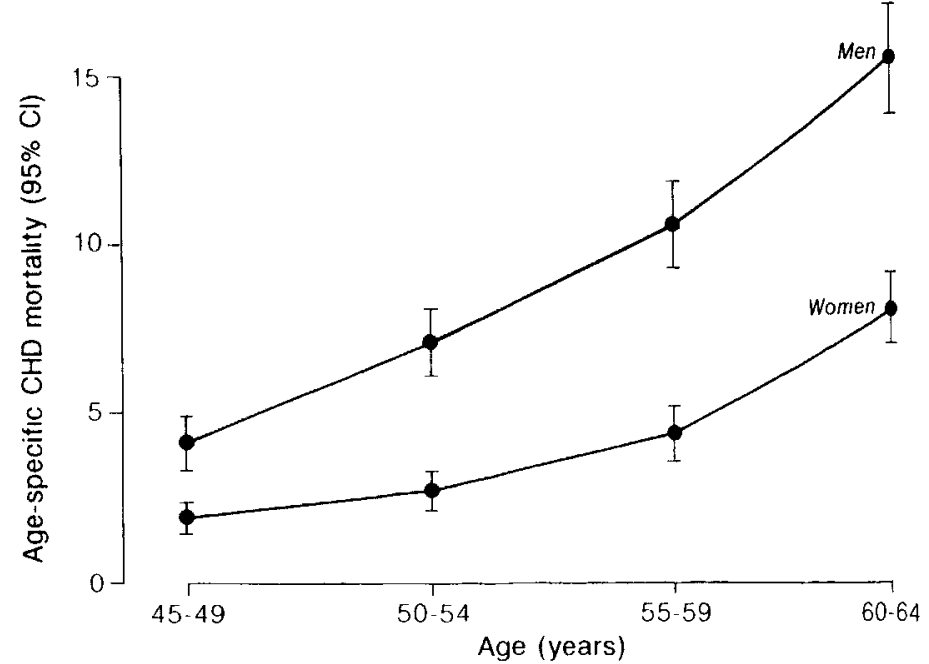

Fig 5-Age-specific CHD mortality (95\% CI) adjusted for all other risk markers.

$p<0.001$ for differences between sexes at all ages

The possibility that absolute risk was lower in women because women are protected by female sex hormones was investigated by calculating age-specific coronary death rates in both sexes after adjustment for all other risks (fig 5). Our results are consistent with this hypothesis and show that women have a substantially lower coronary mortality than men at every age studied. Although the gradient of risk tended to steepen in older women, postmenopausal women aged 60-64 years still had the same risk of coronary death as men 5-10 years younger and only half the coronary mortality of men aged $60-64$ years.

\section{Discussion}

A recurring feature in most reviews about coronary prevention is the lack of data on women. ${ }^{2}$ Few longitudinal studies on cholesterol ${ }^{8-12}$ and only three of the major cholesterol-lowering drug trials ${ }^{13-15}$ included women.

The Renfrew and Paisley survey is one of very few longitudinal health surveys in the UK to provide mortality data for women. The Scottish Heart Health Study ${ }^{16,17}$ will give results for women in Scotland, but the screening survey has only recently been completed and it may be some time before mortality data are available. A case-control study of coronary risk factors among UK women has been published, but this did not include measurement of serum cholesterol. ${ }^{18}$ One further advantage of the Renfrew and Paisley survey is the large number of coronary deaths in women (490), which is greater than the combined total of female coronary deaths (384) published in five other large surveys. ${ }^{8-12}$

The main limitations of our study are the lack of morbidity data and the absence of repeated measurements of risk markers during follow-up. ${ }^{19}$ Death and its cause were certified by general practitioners but were not verified by independent observers. This method has disadvantages but is unlikely to introduce systematic bias. ${ }^{19}$ Our approach has also been used by the Registrar General in his analysis of national statistics on CHD. Moreover, it is unlikely that cancer deaths will have been wrongly classified because the existence of a cancer registry in the west of Scotland allowed for independent confirmation.

Renfrew and Paisley have an especially high incidence of coronary disease. Our results indicate that the distribution of risk markers is different in men and women (table $\mathrm{I}$, figs 1 and 2); that "dose responses" exist for cholesterol, cigarette smoking, diastolic blood pressure, and social class in both 
sexes (figs 3 and 4); and that relative risks are similar in men and women (table II), although absolute and attributable risk are very much lower in women (table II, figs 3 and 4),

The reasons underlying the lower incidence of $\mathrm{CHD}$ in women remain unclear. Women may have a lower frequency of risk markers than men. Our survey suggests that they smoke less and have similar blood pressure, but have higher cholesterol and are more likely to be obese and of lower social class. However, the lower level of smoking among women cannot be the whole explanation for the difference in death rates because non-smoking women have only half the coronary mortality of non-smoking men (fig 4). Similar findings have been reported from other centres. ${ }^{8}$ The social class differences between men and women are difficult to interpret because housewives and retired women assume their husbands' or fathers' social class. The large proportion of women who belong to social classes 4 and 5 is, however, likely to reflect unmarried women employed in textile, clothing, clerical, and service industries.

Women may tolerate risks better than men. We found that, in women, any given level of risk marker was associated with lower CHD rates than men. This protection might be conferred by female sex hormones. Our data are consistent with this explanation: even in women who were 60-64 years initially, CHD rates were substantially lower than in men of similar age, suggesting that natural oestrogen may protect for many years beyond the menopause (fig 5 ).

High-density lipoprotein (HDL) cholesterol was not measured routinely in our survey, although data from other centre ${ }^{20}$ confirm that HDL is higher in women than in men and suggest that this difference may explain the lower female coronary rate. The relation between gender, lipoproteins, and coronary risk is complex, and a small sex difference in $\mathrm{HDL}$ concentration is unlikely to be entirely responsible for the large differences in CHD mortality that exist in Renfrew and Paisley. Non-contraceptive hormones in postmenopausal women may also confer protection against $\mathrm{CHD},{ }^{20}$ but the frequency of hormone replacement therapy in Renfrew and Paisley was not recorded, although it is likely to have been low in the early 1970 s. Triglyceride may have a more important influence on CHD risk in women than in men, ${ }^{21}$ but it is unlikely that this could account for the sex differences observed in our study.

Several areas of uncertainty remain. Despite the lower incidence of CHD among women generally, diabetic women may have the same absolute risk of developing CHD as diabetic men. ${ }^{8}$ Furthermore, women might be more likely than men to have angina or painless myocardial infarction as their initial presentation ${ }^{8}$ and there are no sex differences in prognosis after myocardial infarction..$^{22}$

How should women be advised? They should be urged not to smoke and to stop if they do smoke. ${ }^{23}$ The evidence that control of blood pressure reduces the risk of myocardial infarction is weaker for women than it is for men, ${ }^{24}$ but treatment of hypertension should be recommended because it is of proven value in the reduction of stroke in both sexes. ${ }^{25}$ Regular physical exercise may protect against $\mathrm{CHD}$, although such advice is derived from studies in men. ${ }^{26}$

Although body mass index was not an independent risk factor for $\mathrm{CHD}$ in our study, advice that obese women should lose weight is justified on general health grounds, and because weight loss is likely to facilitate management of hypertension and hyperlipidaemia. Indices of central obesity, such as waist-to-hip ratio and subscapular skin fold, may have greater predictive power than body mass index for $\mathrm{CHD},{ }^{27}$ but neither were measured in Renfrew and Paisley.
Only three lipid-lowering studies have included women. ${ }^{13-15}$ The first was a study of patients with preexisting heart disease $\mathrm{e}^{13}$ and the second was of patients with familial hypercholesterolaemia. ${ }^{14}$ Both studies suggested a benefit to women, but neither addressed the issue of primary prevention of $\mathrm{CHD}$ in women with moderately raised increases of their serum cholesterol. A third study was a secondary prevention trial in which the effects of cholestyramine and placebo on atheroma progression were compared; its results were inconclusive.

Definitive guidelines for the treatment of hypercholesterolaemia in women must await the results of further clinical trials. These will not be available for several years and until then any recommendations for women will have to be judged from estimates of risk rather than of benefit from reduction of risk. If absolute or attributable risk is the criterion on which such judgments should be based, the results of our survey suggest that for primary prevention of CHD the threshold for introduction of cholesterollowering drug therapy should be higher in women than in men.

\section{REFERENCES}

1. Tunstall-Pedoe H, Smith WCS, Crombie IK. Levels and trends of coronary heart disease mortality in Scotland compared with other countries. Health Bull 1986; 44: 153-61.

2. European Atherosclerosis Society Study Group. Strategies for the prevention of coronary heart disease: a policy statement of the European Atherosclerosis Society. Eur Heart f 1987; 8: 77-88.

3. World Health Organisation. International classification of diseases, 9th revision. Geneva: WHO, 1977.

4. Alderson MR, Bayliss RIS, Clarke CA, Whitfield AGW. Death certification. $B r$ Med f 1983; 287: 444-45.

5. Isles CG, Walker LM, Beevers DG, et al. Mortality in patients of the Glasgow Blood Pressure Clinic. 7 Hypertension 1986; 4: 141-56.

6. Hawthorne VM, Greaves DA, Beevers DG. Blood pressure in a Scottish town. $B r$ Med f 1974; 3: 600-03.

7. Garrow JS. Treat obesity seriously. Edinburgh: Churchill Livingstone, 1981.

8. Lemer DJ, Kannel WB. Patterns of coronary heart disease morbidity and mortality in the sexes: a 26 year follow up of the Framingham population. Am Heart f 1986; 111: 383-90.

9. Bush TL, Criqui MH, Cowan LD, et al. Cardiovascular disease mortality in women: results from the Lipid Research Clinics follow up study. In: Eaker E, Packard B, Wenger N, et al, eds. Coronary heart disease in women. New York: Haymarket Doyma, 1987: 106-11.

10. Barrett-Connor E, Khaw KT, Wingard DL. A ten year prospective study of coronary heart disease mortality among Rancho Barnardo women. In: Eaker E, Packard B, Wenger N, et al, eds. Coronary heart disease in women. New York: Haymarket Doyma, 1987: 117-21.

11. Perlman JA, Wolf PH, Ray R, Lieberknecht G. Cardiovascular risk factors, premature heart disease and all cause mortality in a cohort of Northern California women. Am $\mathcal{F}$ Obstet Gynecol 1988; 158: 1568-74.

12. Higgins $M$, Keller JB, Ostrander LD. Risk factors for coronary heart disease in women: Tecumseh Community Health Study 1959-1980. In: Eaker E, Packard B, Wenger N, et al, eds. Coronary heart disease in women. New York: Haymarket Doyma, 1987: 83-89.

13. Ornish D, Brown SE, Scherwitz LW, et al. Can lifestyle changes reverse coronary heart disease? Lancet 1990; 336: 129-33.

14. Kane JP, Malloy MJ, Ports TA, Phillips NR, Diehl JC, Havel RJ. Regression of coronary atherosclerosis during treatment of familial hypercholesterolemia with combined drug regimens. FAMA 1990; 264: 3007-12.

15. Brensike JF, Levy RI, Kelsey SF, et al. Effects of therapy with cholestyramine on progression of coronary arteriosclerosis: results of the NHLBI Type II coronary prevention study. Circulation 1984; 69: 313-24.

16. Smith WCS, Tunstall-Pedoe $\mathrm{H}$, Crombie IK, Tavendale R. Concomitants of excess coronary deaths - major risk factor and lifestyle findings from 10359 men and women in the Scottish Heart Health Study. Scot Med f 1989; 34: 550-55.

17. Tunstall-Pedoe H, Smith WCS, Crombie IK, Tavendale R. Coronary risk factor and lifestyle variation across Scotland: results from the Scottish Heart Health Study. Scot Med f 1989; 34: 556-60.

18. Thompson SG, Greenberg G, Meade TW. Risk factors for stroke and myocardial infarction in women in the UK as assessed in general practice: a case control study. Br Heart f 1989; 61: 403-09. 
19. Isles CG, Lever AF, Hole DJ, Gillis CR, Hawthorne VM. Plasma cholesterol, coronary heart disease and cancer in the Renfrew and Paisley Survey. Br Med J 1989; 298: 920-24.

20. Bush TL, Barrett-Connor E, Cowan LD, et al. Cardiovascular mortality and non-contraceptive use of estrogen in women: results from the Lipid Research Clinics programme follow up study. Circulation 1987; 75 : $1102-09$.

21. Austin MA. Plasma triglyceride as a risk factor for coronary heart disease. Am f Epidemiol 1989; 129: 249-59.

22. Dittrich H, Gilpin E, Nicod P, Cali G, Henning H, Ross J. Acute myocardial infarction in women: influence of gender on mortality and prognostic variables. Am $\mathscr{F}$ Cardiol 1988; 62: 1-7.
23. Rosenberg L, Palmer JR, Shapiro S. Decline in the risk of myocardial infarction among women who stop smoking. N Engl f Med 1990; 322: 213-17.

24. Silman AJ. Hypertension in women: a separate case for treatment? Br Med J 1984; 289: 1021-22.

25. Medical Research Council Working Party. MRC trial of treatment of mild hypertension: principal results. $\mathrm{Br} \operatorname{Med} \mathcal{F} 1985$; 2: 97-104

26. Paffenbarger RS, Hide PHR'T, Wing AL, Hsieh C-C. Physical activity, all cause mortality and longevity of college alumni. N Engl I Med 1986; 314: 605-13.

27. Donahue RP, Abbott RD, Bloom E, Reed DM, Yano K. Central obesity and coronary heart disease in men. Lancet 1987; i: 821-24.

\section{SHORTREPORTS}

\section{Glomerulonephritis with end-stage liver disease in childhood}

\section{G. NOBLE-JAMIESON \\ P. JOHNSTON P. FRIEND \\ S. THIRU \\ N. D. BARNES}

Renal biopsies were done perioperatively in 18 children receiving liver grafts. All specimens showed glomerulonephritis, which was mesangialproliferative in 15 and mesangio-capillary in 3 . Of the 16 children who were alive four or more months after transplantation, only 1 showed progressive deterioration of renal function; 1 other had a subnormal but static glomerular filtration rate. In all 6 children who had proteinuria before operation, the urine became normal.

Lancet 1992; 339:706-07.

The association of nephropathy with chronic liver disease has been thought infrequent. ${ }^{1}$ Now that transplantation has become an accepted treatment for end-stage liver disease the question assumes greater importance: glomerulonephritis might complicate the postoperative course and worsen the long-term outcome. In 5 children with liver disease due to alpha-1-antitrypsin deficiency, evidence of renal dysfunction led us to do renal biopsies, and in every case the kidney showed abnormalities. We therefore investigated the association systematically in a further 13 children receiving first liver grafts.

The study was approved by an ethics committee and no parents withheld consent. This report includes the original 5 children with alpha-1-antitrypsin deficiency. The 13 children in the prospective series had liver disease of various causation (see table), and renal biopsy was done during liver grafting. These patients were selected consecutively unless at operation the procedure was judged dangerous (there were no complications). The specimens were divided and processed for routine histological examination, frozensection immunofluorescence, and electronmicroscopy.

All 18 biopsy specimens showed abnormalities (see table): 15 children had a mesangialproliferative glomerulonephritis (immune staining positive for $\operatorname{IgA}$ in 8 and for $\operatorname{Ig} M$ in 1; diffuse immune complex staining in 1). 3 children had mesangio-capillary glomerulonephritis. Tubular changes (mild necrosis) were seen in only 1 patient, who had potassium wasting disease.

16 children survived to follow-up at 4-34 months (mean 5 months). The urine became normal in all 7 who had shown proteinuria or haematuria before operation (proteinuria 3, proteinuria/haematuria 3, haematuria 1). Only 1 child showed clear long-term deterioration in renal function postoperatively: she had mesangio-capillary glomerulonephritis, and her glomerular filtration rate declined from normal to $25 \%$ in the year after transplantation. Another child, who had mesangialproliferative glomerulonephritis and a scarred right kidney, had a subnormal $(25 \%)$ but stable glomerular filtration rate.

Blood-pressures tended to rise postoperatively (table), and 7 children had seizures or encephalopathy within the

PATIENT DETAILS

\begin{tabular}{|c|c|c|c|c|c|c|c|}
\hline \multirow[b]{2}{*}{ Patient } & \multirow[b]{2}{*}{ Diagnosis } & \multirow[b]{2}{*}{ Age $(y r)$} & \multicolumn{2}{|c|}{ Renal biopsy } & \multicolumn{2}{|c|}{$\begin{array}{l}\text { Highest mean arterial } \\
\text { pressure (SD score) }\end{array}$} & \multirow{2}{*}{$\begin{array}{l}\text { Central nervous } \\
\text { system complications }\end{array}$} \\
\hline & & & Histology & Immune staining & Preop & Postop & \\
\hline $1^{\star}$ & Antitrypsin deficiency & $14 \cdot 5$ & MPGN & Not done & $93(+1 \cdot 0)$ & $130(+4 \cdot 6)$ & Encephalopathy (day 4) \\
\hline $2^{\star}$ & Antitrypsin deficiency & $8 \cdot 2$ & MPGN & Negative & $102(+2 \cdot 8)$ & $145(+7 \cdot 3)$ & Seizure/encephalopathy (day 6) \\
\hline $3^{\star}$ & Antitrypsin deficiency & $3 \cdot 8$ & MPGN & $\operatorname{Ig} A$ & $93(+2 \cdot 2)$ & $126(+5 \cdot 4)$ & Encephalopathy (day 7) \\
\hline $4^{\star}$ & Antitrypsin deficiency & $5 \cdot 6$ & MCGN & $\mathrm{N} / \mathrm{A}$ & $86(+1.5)$ & $125(+5 \cdot 4)$ & Seizure/encephalopathy (day 26) \\
\hline $5^{\star}$ & Antitrypsin deficiency & $8 \cdot 5$ & MCGN & N/A & $93(+2 \cdot 0)$ & $114(+4 \cdot 0)$ & Nil \\
\hline 6 & Biliary atresia & $3 \cdot 4$ & MPGN & Immune complex & $87(+1.8)$ & $104(+3 \cdot 3)$ & Nil \\
\hline 7 & Biliary atresia & $12 \cdot 2$ & MCGN & N/A & $107(+2.5)$ & $135(+5 \cdot 1)$ & Nil \\
\hline 8 & Familial cirrhosis & $6 \cdot 2$ & MPGN & IgA & $72(0.0)$ & $112(+4 \cdot 1)$ & Seizure (day 21 ) \\
\hline 9 & Biliary atresia & $1 \cdot 6$ & MPGN & Negative & $93(+2 \cdot 0)$ & $82(+1 \cdot 3)$ & Nil \\
\hline 10 & Dicarboxylic aciduria & $3 \cdot 4$ & $M P G N$ & $\operatorname{Ig} A$ & $70(0.0)$ & $101(+3 \cdot 1)$ & Nil \\
\hline 11 & Alagille syndrome & $13 \cdot 8$ & MPGN & Not done & $93(+0 \cdot 8)$ & $90(+0.8)$ & Nil \\
\hline 12 & Biliary atresia & 1.9 & MPGN & $\operatorname{IgA}$ & $70(0 \cdot 0)$ & $83(+1 \cdot 4)$ & Nil \\
\hline 13 & Antitrypsin deficiency & 0.9 & MPGN & $\operatorname{Ig} A$ & $77(+1-0)$ & $101(+3 \cdot 3)$ & Nil \\
\hline 14 & Tyrosinaemia & $3 \cdot 9$ & MPGN & $\operatorname{Ig} M$ & $82(+1 \cdot 0)$ & $110(+3.9)$ & Nil \\
\hline 15 & Biliary atresia & $8 \cdot 4$ & MPGN & Not done & $65(-1.0)$ & $112(+3 \cdot 8)$ & Seizure (day 23) \\
\hline 16 & Biliary atresia & $11 \cdot 1$ & MPGN & $\operatorname{IgA}$ & $92(+1.5)$ & $103(+2 \cdot 4)$ & Seizure (day 13) \\
\hline 17 & Biliary atresia & $13 \cdot 8$ & MPGN & $\operatorname{IgA}$ & $80(0.0)$ & $97(+1.3)$ & Nil \\
\hline 18 & Biliary atresia & $1 \cdot 8$ & MPGN & IgA & $95(+2 \cdot 5)$ & $113(+4 \cdot 3)$ & Nil \\
\hline
\end{tabular}

*Patıents studied before prospectıve serıes. MPGN = mesangialproliferative glomerulonephritıs $\mathrm{MCGN}=$ mesangıo-capillary glomerulonephritıs. N/A= not applicable 